\title{
Model Generalized Space Time Autoregressive (GSTAR) dengan Analisis Data Menggunakan Software $R$
}

\author{
Yulianti Talungke ${ }^{1}$, Nelson Nainggolan ${ }^{2}$, Djoni Hatidja ${ }^{3}$ \\ ${ }^{1}$ Program Studi Matematika, FMIPA, UNSRAT Manado, talungkeyulianti@yahoo.co.id \\ ${ }^{2}$ Program Studi Matematika, FMIPA, UNSRAT Manado, bapaivana@yahoo.com \\ ${ }^{3}$ Program Studi Matematika, FMIPA, UNSRAT Manado, dhatidja@ yahoo.com
}

\begin{abstract}
Abstrak
Tujuan penelitian ini adalah menganalisis data model Generalized Space Time Autoregreesive (GSTAR) menggunakan software R. Data yang digunakan adalah data inflasi di Kota Manado, Palu, dan Makasar periode bulan Januari 2010 sampai dengan bulan Desember 2014. Data diolah menggunakan software R, mulai dari menginput data, memplotkan data, menaksir parameter, membuat model, sampai uji diagnostik. Hasil penaksiran parameter model GSTAR untuk data inflasi tiga lokasi memberikan taksiran parameter $0.085,0.022,0.380$ dan $0.245,0.458,0.164$. sehingga diperoleh model GSTAR untuk tiga lokasi adalah

$$
\begin{aligned}
& \hat{Z}_{1}(t)=0.085 Z_{1}(t-1)+0.1225 Z_{2}(t-1)+0.1225 Z_{3}(t-1) \\
& \hat{Z}_{2}(t)=0.022 Z_{2}(t-1)+0.214 Z_{1}(t-1)+0.214 Z_{3}(t-1) \\
& \hat{Z}_{3}(t)=0.380 Z_{3}(t-1)+0.082 Z_{1}(t-1)+0.0820 Z_{2}(t-1) .
\end{aligned}
$$
\end{abstract}

Kata Kunci: Model GSTAR, Software R, Time Series

\section{Generalized Space Time Autoregressive (GSTAR) Model with Data Analysis Using R Software}

\begin{abstract}
The purpose of this research is to Generalized Space Time Autoregressive (GSTAR) data model using $R$ software. Data that used in this analysis are inflation data in Manado, Palu, dan Makasar from period Januari 2010 until December 2014. It used $R$ software to process from input data, plot data, estimate parameter, made model and until diagnostic test. The result of GSTAR's estimating parameter model in three different are 0.085, 0.022, 0.380 dan 0.245, 0.458, 0.164. so that the GSTAR's model for three location are

$$
\begin{aligned}
& \hat{Z}_{2}(t)=0.022 Z_{2}(t-1)+0.214 Z_{1}(t-1)+0.214 Z_{3}(t-1) \\
& \hat{Z}_{3}(t)=0.380 Z_{3}(t-1)+0.082 Z_{1}(t-1)+0.0820 Z_{2}(t-1) .
\end{aligned}
$$$$
\hat{Z}_{1}(t)=0.085 Z_{1}(t-1)+0.1225 Z_{2}(t-1)+0.1225 Z_{3}(t-1)
$$

Keywords: GSTAR Model, Software R, Time Series

\section{Pendahuluan}

Dalam kehidupan sehari-hari, banyak dijumpai data tersebut. Untuk meramalkan data dengan jenis tersebut dapat digunakan metode peramalan yang dapat menggabungkan kedua unsur tersebut. Model yang dapat menggabungkan unsur waktu dan lokasi disebut model space time. Model Generalized Space Time Autoregressive (GSTAR) menghasilkan model space time dengan parameter-parameter yang tidak harus sama untuk waktu maupun lokasi[1]. Dalam menganalisis data untuk model GSTAR digunakan software untuk membantu mempermudah dalam perhitungan.

Ada beberapa software yang dapat digunakan, misalnya Minitab, S-Plus, dan lain-lain. R juga merupakan salah satu software yang dapat digunakan. Banyak keunggulan yang ditawarkan oleh software R, misalnya bersifat multiplatforms (tersedia untuk sistem operasi windows, Linux, Macintosh dan Unix), reliabilitas dari software yang baik, ketersediaan update dan library yang lengkap, fasilitas help untuk pengguna yang bersifat free of charge, dan lain-lain. Fungsionalitas dan kemampuan dari $R$ sebagian besar diperoleh dari Add-on packages/library[2]. 
Penelitian ini merupakan tindak lanjut dari penelitian sebelumnya, tentang model Generalized Space Time Autoregressive (GSTAR) pada prediksi harga beras dibeberapa kabupaten/kota yang menggunakan sofware S-Plus dalam penentuan parameter-parameternya[3]. Namun dalam penelitian ini, untuk analisa model GSTAR digunakan software R.

\section{Model Generalized Space Time Autoregressive (GSTAR)}

Model Generalized Space Time Autoregressive (GSTAR) merupakan perluasan dari model STAR. Perbedaan mendasar antara keduanya adalah pengasumsian parameternya. Pada model STAR parameternya tidak bergantung pada lokasi, sehingga model STAR hanya sesuai untuk lokasi-lokasi yang homogen. Sedangkan pada model GSTAR, parameter model berubah-ubah untuk setiap lokasi.

Model GSTAR orde $p$ dirumuskan sebagai berikut [4] :

$$
Z_{t}=\sum_{s=1}^{p}\left[\phi_{s 0}+\sum_{k=1}^{\lambda_{s}} \phi_{s k} w^{k}\right] \boldsymbol{Z}_{(t-s)}+\boldsymbol{\varepsilon}_{(t)}
$$

Persamaan model GSTAR dengan menggunakan 3 lokasi yang berbeda dalam bentuk matriks ditulis sebagai berikut

$$
\begin{aligned}
{\left[\begin{array}{l}
Z_{1}(t) \\
Z_{2}(t) \\
Z_{3}(t)
\end{array}\right] } & =\left[\begin{array}{ccc}
\phi_{10} & 0 & 0) \\
0 & \phi_{20} & 0 \\
0 & 0 & \phi_{30}
\end{array}\right]\left[\begin{array}{c}
Z_{1}(t-1) \\
\left.Z_{2} t-1\right) \\
\left.Z_{3} t-1\right)
\end{array}\right] \\
& +\left[\begin{array}{ccc}
\phi_{11} & 0 & 0) \\
0 & \phi_{21} & 0 \\
0 & 0 & \phi_{31}
\end{array}\right]\left[\begin{array}{ccc}
0 & w_{12} & w_{13} \\
w_{21} & 0 & w_{23} \\
w_{31} & w_{32} & 0
\end{array}\right]\left[\begin{array}{c}
Z_{1}(t-1) \\
\left.Z_{2} t-1\right) \\
\left.Z_{3} t-1\right)
\end{array}\right]+\left[\begin{array}{l}
\varepsilon_{1}(t) \\
\varepsilon_{2}(t) \\
\varepsilon_{3}(t)
\end{array}\right]
\end{aligned}
$$

Matriks bobot $w$ dalam lag spasial $l$ berupa matriks bujur sangkar $(N \times N)$ yang dapat dituliskan dengan :

$$
\left[\begin{array}{cccc}
0 & w_{12} & \ldots & w_{1 N} \\
w_{21} & 0 & \ldots & w_{2 N} \\
\vdots & \vdots & \ldots & \vdots \\
w_{N 1} & w_{N 2} & \ldots & 0
\end{array}\right]
$$

Penentuan bobot matriks w dalam lag spasial $l$ secara umum bergantung pada cara melihat lokasi. Pemilihan bobot lokasi adalah salah satu permasalahan utama dalam pemodelan GSTAR. Bobot seragam hanya ditentukan oleh jumlah dari lokasi tertentu dengan range jarak tertentu. Bobot seragam dihitung dengan rumus

$$
w_{i j}=\frac{1}{n_{i}}
$$

Bobot lokasi digunakan untuk data yang lokasinya homogen atau mempunyai jarak antar lokasi yang sama.

Penaksiran parameter model GSTAR dilakukan menggunakan metode kuadrat terkecil dengan meminimumkan jumlah kuadrat simpangannya. Maka model persamaan untuk lokasi ke- $i$ dapat ditulis sebagai berikut.

$$
\begin{gathered}
Y_{i}=X_{i} \beta_{i}+\varepsilon_{i} \\
Y_{i}=\left[\begin{array}{c}
Z_{i}(i-1) \\
Z_{i}(i-2) \\
\vdots \\
Z_{i}(i-T)
\end{array}\right], X_{i}=\left[\begin{array}{cc}
Z_{i}(0) & V_{i}(0) \\
Z_{i}(1) & V_{i}(1) \\
\vdots & \vdots \\
Z_{i}(i-T) & V_{i}(T-1)
\end{array}\right] \text {, dan } \varepsilon_{i}=\left[\begin{array}{c}
\varepsilon_{i}(1) \\
\varepsilon_{i}(2) \\
\vdots \\
\varepsilon_{i}(T)
\end{array}\right]
\end{gathered}
$$

Persamaan model untuk semua lokasi secara serentak mengikuti struktur model linear $Y=X \beta+\varepsilon$, dengan $Y=\left(Y_{1}{ }^{\prime}, \ldots, Y_{N}{ }^{\prime}\right), \quad X=\operatorname{diag}\left(X_{1}, \ldots, X_{N}\right), \quad \beta=\left(\beta_{1}{ }^{\prime}, \ldots, \beta_{N}{ }^{\prime}\right)^{\prime}, \quad$ dan $\varepsilon=\left(\varepsilon_{1}{ }^{\prime}, \ldots, \varepsilon_{N}{ }^{\prime}\right)^{\prime}$. Metode kuadrat terkecil adalah meminimumkan jumlah kuadrat dari galat yaitu $\sum \varepsilon_{i}{ }^{2}$. 
Uji diagnostik adalah uji yang dilakukan untuk menguji kesesuian model.Uji diagnostik perlu dilakukan untuk membuktikan bahwa model tersebut cukup memadai dan menentukan model mana yang terbaik untuk peramalan [5].

Analisis data tidak dapat dilakukan tanpa teknik yang tepat. Artinya, analisis yang handal seharusnya memanfaatkan keakurasian dan kecepatan perhitungan dengan paket komputasi statistik Software $R$ digunakan dalam menganalisis data. $\mathrm{R}$ menyediakan berbagai teknik statistika (permodelan linier dan nonlinier, uji statistik klasik, analisis deret waktu, klasifikasi, klasterisasi, dan sebagainya) serta grafik.Untuk keperluan analisa time series, telah tersedia cukup lengkap paket atau library dari $R$.

\section{Metodologi Penelitian}

Prosedur atau tahapan-tahapan yang akan dilakukan dalam penelitian ini, adalah sebagai berikut:.

1. Data

Data yang akan digunakan adalah data inflasi di Kota Manado, Palu, dan Makasar periode bulan Januari 2010 sampai dengan bulan Desember 2014.

2. Stasioneritas data

Data inflasi di Kota Manado, Palu, dan Makasar akan diuji kestasionerannya untuk memperkecil kekeliruan model, jika data tidak stasioner dalam rata-rata harus dilakukan proses selisih (differencing).

3. Identifikasi Model

Model time series dikatakan baik apabila kesalahan (error) kecil. Dengan menggunakan plot ACF dan PACF dapat ditentukan model ARIMA.

4. Estimasi Parameter

Untuk menaksir parameter yang digunakan adalah Metode Kuadrat Terkecil (Least Square Method) dengan menggunakan Software R.

5. Uji Diagnostik

Dalam penaksiran parameter, dilakukan uji diagnosis untuk melihat apakah galat (error) yang dihasilkan sudah berdistribusi normal dan layak untuk digunakan.

6. Prediksi

Model GSTAR yang diperoleh digunakan untuk memprediksi data inflasi di Kota Manado, Palu dan Makasar.

\section{Hasil Dan Pembahasan}

\subsection{Analisis Data Model GSTAR Menggunakan Software $\mathbf{R}$}

Data yang akan digunakan untuk dianalisis adalah data Inflasi tiga kota di Sulawesi, yaitu Kota Manado, Kota Palu, dan Kota Makasar periode bulan Januari 2010 sampai dengan bulan Desember 2014. Berikut akan dianalisa model GSTAR dengan data inflasi tersebut menggunakan software R.

berikut :

Menginput data inflasi kota Manado, Palu, dan Makasar dalam software R adalah sebagai

Inflasi.Mdo $=\mathrm{c}(0.41,0.49, \ldots, 1.42,1.56,3.83)$, data yang digunakan sebanyak 60 data, yaitu data inflasi kota Manado mulai bulan Januari 2010 sampai dengan bulan Desember 2014

Inflasi.Palu $=c(0.12,-0.1, \ldots, 1.31,0.21,2.68)$, data yang digunakan sebanyak 60 data, yaitu data inflasi kota Palu pada bulan Januari 2010 sampai dengan Desember 2014.

Inflasi.Mksr $=c(1.3,0.1, \ldots, 0.43,1.36,2.69)$, data yang digunakan sebanyak 60 data. Yaitu data inflasi kota Makasar antara bulan Januari 2010 sampai dengan Desember 2014. berikut:

Memplotkan data inflasi kota Manado, Palu, dan Makasar dalam software R adalah sebagai 


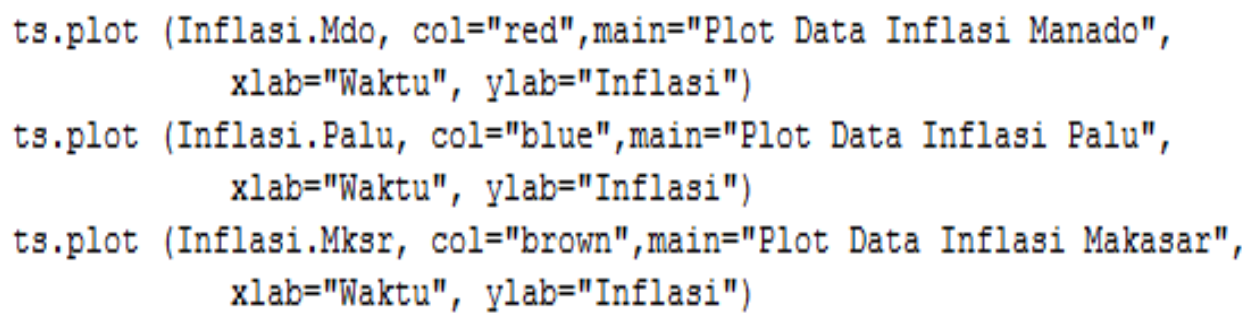

Plot data inflasi kota Manado, Palu dan Makasar disajikan pada Gambar 1, 2, dan 3.

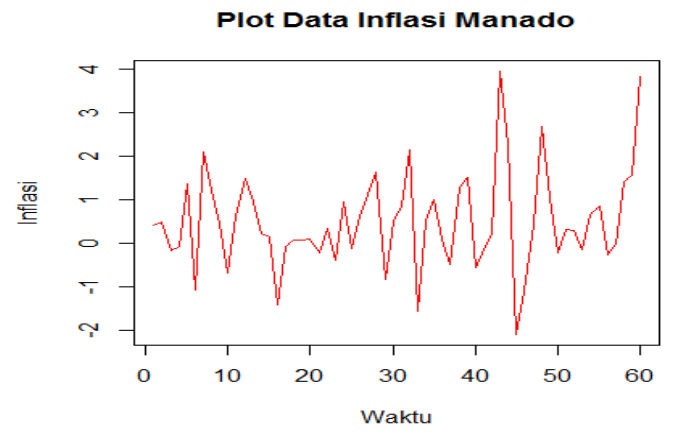

Gambar 1. Plot Data Inflasi Kota Manado Periode Bulan Januari 2010 - Desember 2014

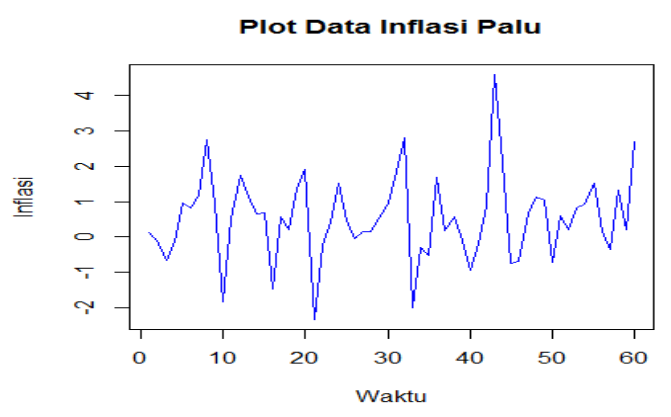

Gambar 2. Plot Data Inflasi Kota Palu Periode Bulan Januari 2010 - Desember 2014

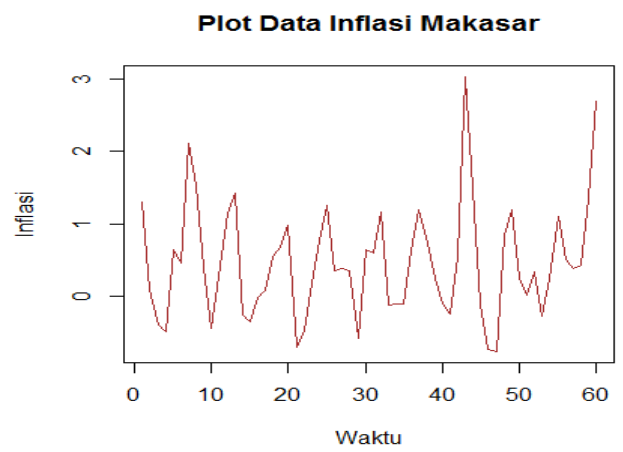

Gambar 3. Plot Data Inflasi Kota Makasar Periode Bulan Januari 2010 sampai dengan Bulan Desember 2014.

Digunakan juga uji Kolmogorov-Smirnov untuk menguji kenormalan data inflasi Manado, Palu, dan Makasar, dengan taraf nyata adalah $95 \%$ atau $\alpha=0.05$. Untuk $\alpha=0,05$ dan derajat bebas $\mathrm{n}=60$ maka dari tabel Kolmogorov Smirnov diperoleh nilai $D_{\alpha}\left(\mathrm{D}_{0,05} ; 60\right)=0,172$. Hasil uji menggunakan uji Kolmogorov-Smirnov dalam Software R adalah seperti berikut.

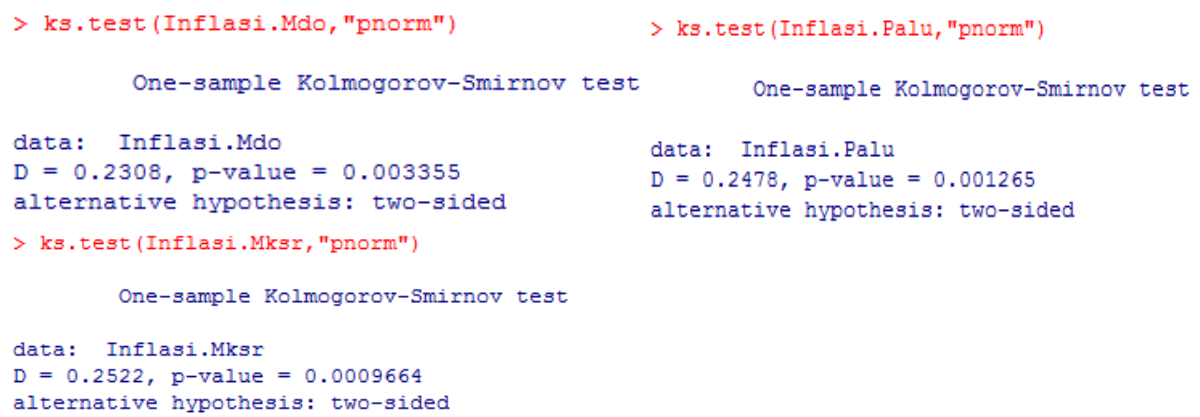

Stasioneritas berarti bahwa tidak terdapat perubahan yang drastis pada data. Fluktuasi data berada disekitar suatu nilai rata-rata yang konstan, tidak tergantung pada waktu dan variansi dari fluktuasi tersebut (Makridakis dkk, 1999). Dari Gambar plot, terlihat bahwa fluktuasi data berada disekitaran satu titik yang konstan. Selain itu, dari hasil uji Kolmogorov-Smirnov perolehan nilai $D=0.2308$ untuk Kota Manado, $D=2478$, untuk Kota Palu, dan $D=0.2522$ untuk Kota Makasar. Dapat dilihat nilai $D$ yang diperoleh dari tiga lokasi tersebut yaitu $D>D_{\alpha}$, dalam artian bahwa data inflasi untuk Kota Manado, Palu, dan Makasar terdistribusi secara normal. Dengan 
demikian dapat dikatakan data inflasi kota Manado, Palu, dan Makasar sudah stasioner dan tidak perlu dilakukan differencing.

\subsection{Penaksiran Parameter Model GSTAR Tiga Lokasi}

Persamaan Model GSTAR untuk tiga lokasi, ditulis sebagai berikut:

$Z_{1}(t)=a_{1} Z_{1}(t-1)+b_{1} w_{12} Z_{2}(t-1)+b_{1} w_{13} Z_{3}(t-1)+\varepsilon_{1}(t)$

$Z_{2}(t)=a_{2} Z_{2}(t-1)+b_{2} w_{21} Z_{1}(t-1)+b_{2} w_{23} Z_{3}(t-1)+\varepsilon_{2}(t)$

$Z_{3}(t)=a_{3} Z_{3}(t-1)+b_{3} w_{31} Z_{1}(t-1)+b_{3} w_{32} Z_{2}(t-1)+\varepsilon_{3}(t)$

Menentukan parameter Model GSTAR menggunakan Metode Kuadrat Terkecil (MKT) adalah

$$
\hat{\mathbf{b}}=\left(\mathbf{X}^{\mathbf{t}} \mathbf{X}\right)^{-\mathbf{1}} \mathbf{X}^{\mathbf{t}} \mathbf{Y}
$$

Nilai-nilai parameter dihitung menggunakan software R, dengan pengolahan data seperti berikut.

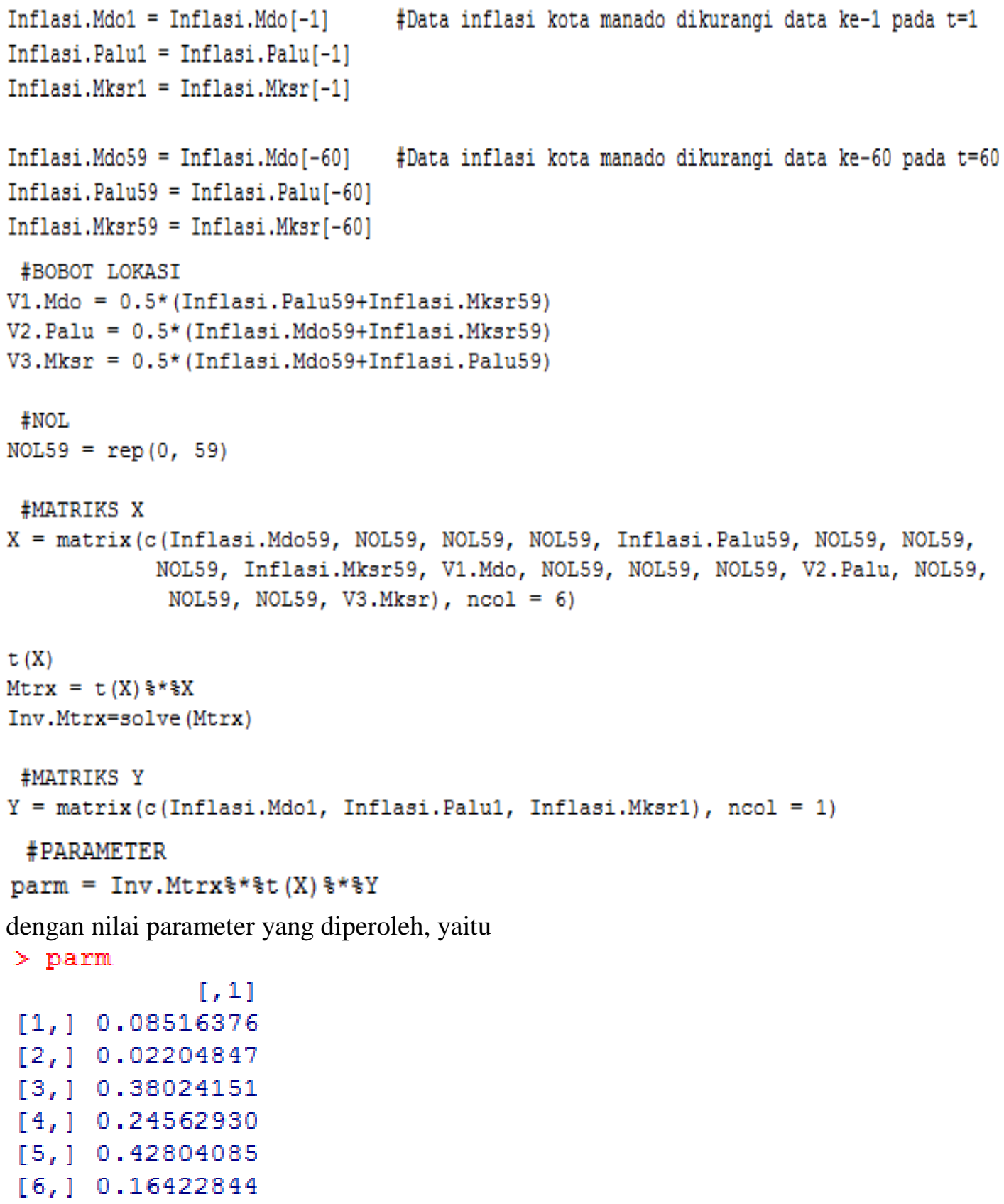


Dari hasil penentuan parameter dan penentuan matriks bobot, selanjutnya akan ditentukan model GSTAR data inflasi kota Manado, Palu, dan Makasar periode bulan Januari 2010 sampai Desember 2014.

$$
\left[\begin{array}{l}
Z_{1}(t) \\
Z_{2}(t) \\
Z_{3}(t)
\end{array}\right]=\left[\begin{array}{l}
0.085 Z_{1}(t-1) \\
0.022 Z_{2}(t-1) \\
0.380 Z_{3}(t-1)
\end{array}\right]+\left[\begin{array}{ccc}
0 & 0.1225 & 0.1225 \\
0.214 & 0 & 0.2140 \\
0.082 & 0.0820 & 0
\end{array}\right]\left[\begin{array}{l}
Z_{1}(t-1) \\
Z_{2}(t-1) \\
Z_{3}(t-1)
\end{array}\right]
$$

Dari persamaan (9) dapat dituliskan model GSTAR untuk prediksi inflasi kota Manado, Palu, dan Makasar, sebagai berikut :

1. Kota Manado : $\hat{Z}_{1}(t)=0.085 Z_{1}(t-1)+0.1225 Z_{2}(t-1)+0.1225 Z_{3}(t-1)$

2. Kota Palu : $\hat{Z}_{2}(t)=0.022 Z_{2}(t-1)+0.214 Z_{1}(t-1)+0.2140 Z_{3}(t-1)$

3. Kota Makasar : $\hat{Z}_{3}(t)=0.380 Z_{3}(t-1)+0.082 Z_{1}(t-1)+0.0820 Z_{2}(t-1)$

\subsection{Prediksi Data Inflasi di Kota Manado, Palu, dan Makasar}

Untuk mengetahui kondisi data Inflasi yang sebenarnya dengan data Inflasi hasil prediksi menggunakan model GSTAR maka dilakukan Prediksi. Prediksi tidak harus memberikan jawaban secara pasti kejadian yang akan terjadi, melainkan mencari jawaban sedekat mungkin yang akan terjadi. Perbandingan data inflasi yang sebenarnya dengan data inflasi hasil prediksi dapat dilihat melalui interpretasi grafik yang dilakukan dalam software R, sebagai berikut:

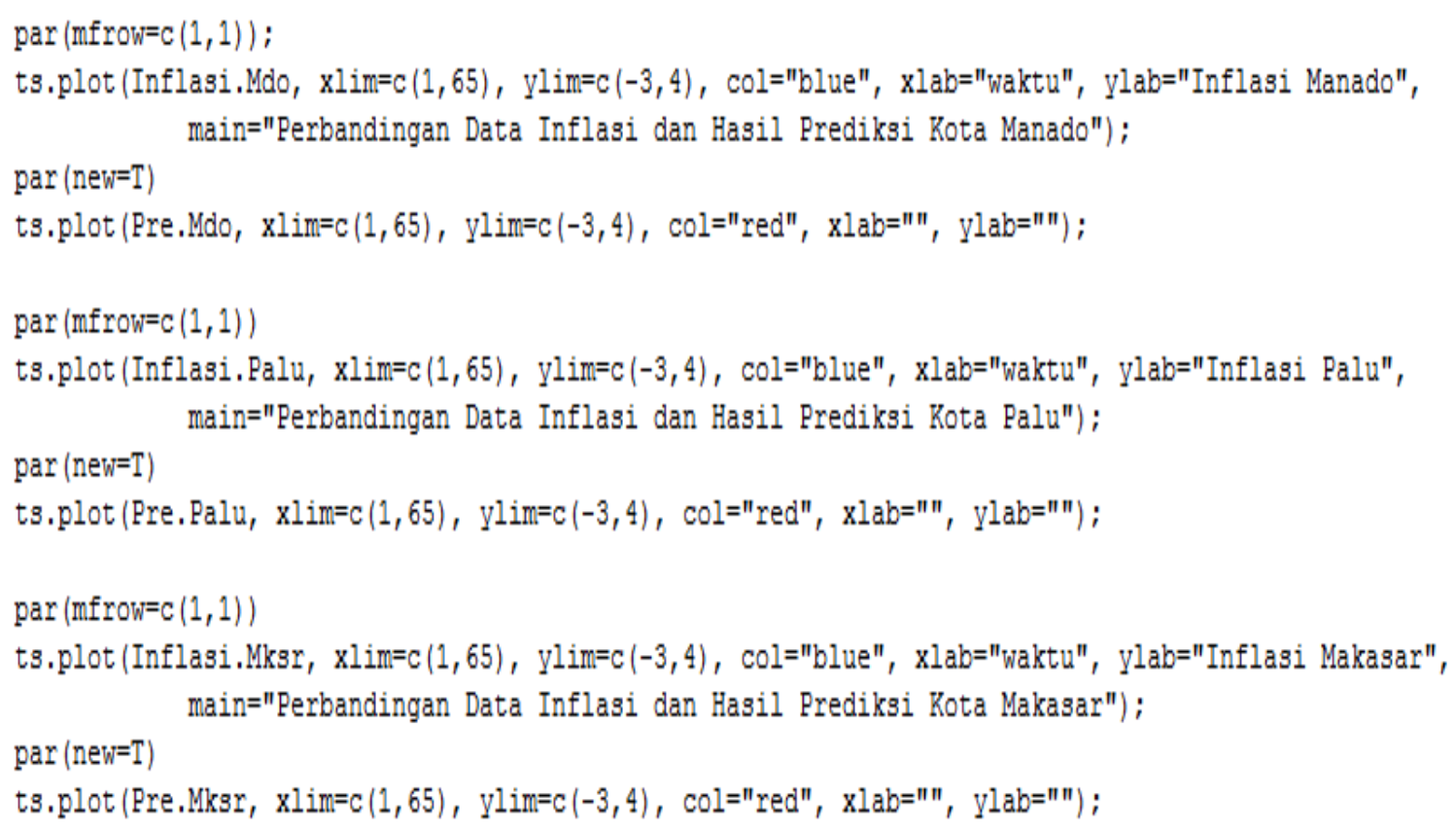

Untuk prediksi Bulan Januari data inflasi Kota Manado, Palu dan Makasar dalam software R, adalah sebagai berikut

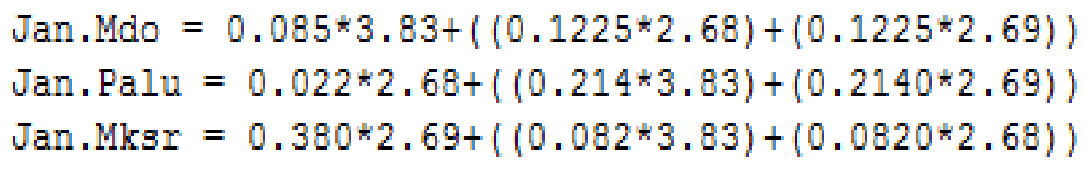

Dengan hasil prediksi yang diperoleh untuk Kota Manado $=0.98$, Kota Palu $=1.45$, dan Kota Makasar $=1.55$. 


\section{Kesimpulan}

Berdasarkan hasil dan pembahasan yang telah dilakukan, maka kesimpulan yang dapat diambil yaitu :

1. Model Generalized Space Time Autoregressive (GSTAR) data dianalisis menggunakan software R. Untuk menganalisis data model GSTAR dilakukan mulai dari menginput data, memplot data untuk menguji kestasioneran data, menaksir parameter, membuat model, dan uji diagnostik pada model yang diperoleh. Model GSTAR untuk data inflasi Kota Manado, Palu, dan Makasar diperoleh secara berturut- turut adalah:

$\hat{\hat{Z}}_{1}(t)=0.085 Z_{1}(t-1)+0.1225 Z_{2}(t-1)+0.1225 Z_{3}(t-1)$,

$\hat{Z}_{2}(t)=0.022 Z_{2}(t-1)+0.214 Z_{1}(t-1)+0.2140 Z_{3}(t-1)$,

$\hat{Z}_{3}(t)=0.380 Z_{3}(t-1)+0.082 Z_{1}(t-1)+0.0820 Z_{2}(t-1)$.

2. Model GSTAR yang diperoleh cukup baik untuk meramal data inflasi ditiga kota tersebut.

\section{Daftar Pustaka}

[1] Ruchjana, B. N. 2002. Pemodelan Kurva Produksi Minyak Bumi Menggunakan Model Generalized STAR. Forum Statistika dan Komputasi, IPB, Bogor.

[2] Latupeirissa, Y. M. A. 2014. Model Generalized Space Time Autoregressive (GSTAR) Orde-1 dan Penerapannya Pada Prediksi Harga Beras di Kota Bitung, Kabupaten Minahasa, dan Kabupaten Minahasa Selatan [Skripsi]. FMIPA UNSRAT. Manado

[3] Rosadi, D. 2009. Pemanfaatan Software Open Source R dalam pemodelan ARIMA. Prosiding Seminar Nasional Matematika dan Pendidikan Matematika; Yogyakarta, 5 Desember 2009. Himpunan Matematika Indonesia (Indo-MS) Wilayah Jateng dan DIY.Hlm 786-795.

[4] Borovkova, S.A, dkk. 2008. Consistency and Asymptotic Normality of Least Square Estimators in Generalized STAR Models. Journal Compilation Statistica Neerlandica, Neerlandica, 62 (4): 482-508. .

[5] Makridakis, S., S.C. Wheelwright dan V.E. McGee. 1999. Metode dan Aplikasi Peramalan Jilid 1 Edisi Kedua.Terjemahan Ir. Untung S. Andriyanto dan Ir. Abdul Basith. Erlangga, Jakarta. 